\title{
Práticas de gestão de custos logísticos internos: estudo de caso em empresa moveleira do sul do Brasil
}

\author{
Management practices of internal logistics costs: case study in a furniture company in \\ southern Brazil
}

Prácticas de gestión de costos logísticos internos: estudio de caso en empresa mueblera del sur de Brasil

\section{Marcos Antonio de Souza}

Doutor em Controladoria e Contabilidade pela Universidade de São Paulo (FEA/USP)

Professor do Programa de Pós-Graduação em Ciências Contábeis da Universidade do Vale do Rio dos Sinos (UNISINOS)

Endereço: Av. Unisinos, n॰ 950, Econômicas, Sala 5A408, Bairro Cristo Rei

CEP: 93.022-000 - São Leopoldo/RS - BRASIL

E-mail: marcosas@unisinos.br

Telefone: +55 (51) 3037-1000, Ramal 1569 - 051 8246-6000

\section{Elson Luciano Weber}

Mestrando do Programa de Pós-Graduação em Ciências Contábeis da Universidade do Vale do Rio dos Sinos (UNISINOS)

Professor de Matemática do Colégio Estadual $\mathrm{Dr}^{\circ}$ Wolfram Metzler

Endereço: Av. Unisinos, n॰ 950, Bairro Cristo Rei

CEP: 93.022-000 - São Leopoldo/RS - BRASIL

E-mail: elsonweber@yahoo.com.br

Telefone: +55 (54) 8155-0746

\section{Rafael Herden Campos}

Mestre do Programa de Pós-Graduação em Ciências Contábeis da Universidade do Vale do Rio dos Sinos (UNISINOS)

Professor do Instituto Federal de Educação, Ciência e Tecnologia Sul-Rio-Grandense

Endereço: Av. Copacabana, n 100, Bairro Piratini

CEP: 93.216-120 - Sapucaia do Sul/RS - BRASIL

E-mail: rcamposrs@yahoo.com.br

Telefone: +55 (51) 3452-9200 ou +55 (51) 9327-5611

Artigo recebido em 20/02/2014. Revisado por pares em 05/12/2014. Reformulado em 09/01/2015. Recomendado para publicação em 06/02/2015 por Sandra Rolim Ensslin (Editora Científica). Publicado em 29/05/2015. 


\title{
Resumo
}

O objetivo do artigo é analisar os processos e práticas da gestão de custos logísticos internos de empresa moveleira brasileira. Trata-se de um estudo de caso único e com abordagem qualitativa. Os dados foram coletados no $3^{\circ}$ trimestre de 2013, com entrevistas com gestores da empresa, análise documental e observação in loco. A análise dos dados teve apoio do Software Sphinx. Os achados indicam que entre os processos da gestão de logística interna o que mais gera custos é o transporte, porém, quando o estoque do varejo é mal gerenciado, gera ônus incremental do custo de oportunidade. Há consistência parcial das práticas do processo logístico em relação à literatura sobre atividades logística e práticas de gestão estratégica de custos.

Palavras-chave: Gestão de custos logísticos. Cadeia de valor interna. Transporte.

\begin{abstract}
The aim of this paper is to analyze the processes and practices of management of internal logistics costs of Brazilian furniture company. It is a study of a single case and with qualitative approach. Data were collected in the third quarter of 2013, with interviews with company managers, document review and on-site observation. Data analysis was supported by the Software Sphinx. The findings indicate that among the processes of internal logistics management the one that generates more costs is transport, but when the retail stock is poorly managed, it generates incremental burden of opportunity cost. There is partial consistency of practices of the logistics process in relation to the literature on logistics activities and strategic management practices costs.
\end{abstract}

Keywords: Logistics cost management. Internal value chain. Transport.

\section{Resumen}

El objetivo del artículo es analizar los procesos y prácticas de la gestión de costos logísticos internos de empresa mueblera brasileña. Se trata de un estudio de caso único y con enfoque cualitativo. Los datos fueron recopilados en el $3^{\circ}$ trimestre de 2013, con entrevistas con gestores de la empresa, análisis documental y observación in loco. El análisis de los datos tuvo el apoyo del Software Sphinx. Las investigaciones indican que entre los procesos de la gestión de logística interna lo que más genera costos es el transporte, sin embargo, cuando el stock del mercado minorista no es bien gestionado, genera una adicional del costo de oportunidad. Hay consistencia parcial de las prácticas del proceso logístico en relación a la literatura sobre actividades logísticas y prácticas de gestión estratégica de costos.

Palabras clave: Gestión de costos logísticos. Cadena de valor interna. Transporte. 


\section{Introdução}

Quanto à análise da cadeia de valor da empresa, objeto desta pesquisa, Shank e Govindarajan (1997) afirmam que ela não pode ser gerenciada de maneira isolada, pois pertence a uma cadeia de atividades integradas que envolvem também outras empresas. Todos os elos dessa cadeia, de uma forma ou de outra, afetam o desempenho interno e externo (clientes e fornecedores) da empresa (PORTER, 1989). Na cadeia de valor de uma empresa, há diversas atividades, dentre as quais aquelas que compreendem a logística. Essas atividades geram custos, que precisam ser gerenciados para melhorar a vantagem competitiva. A logística envolve os processamentos de pedidos, transporte, armazenagem e estocagem, logística interna, embalagens, distribuição e assistência (ENGBLOM et al., 2012). A análise de custos da cadeia de valor é entendida como uma prática que contribui para viabilizar vantagens competitivas em relação a concorrentes (SOUZA; CARDOSO; MACHADO, 2011). Isso justifica a importância da realização de pesquisas sobre essa temática.

Com o acirramento da concorrência entre as empresas e a ampliação do ambiente de negócios nas últimas décadas, em decorrência da globalização dos negócios, as organizações têm procurado desenvolver estratégias que lhes propiciem vantagem competitiva sustentável. Santos et al. (2010) trazem um panorama sobre a desverticalização que vem ocorrendo, em que empresas que antes operavam verticalmente tendem a se horizontalizarem, ou seja, controlam a atividade principal da empresa e terceirizam as demais, desenvolvendo diretamente somente parte do produto final que será entregue ao consumidor.

No âmbito desse novo modus operandi a questão dos custos surge de forma relevante. Nesse contexto, a gestão de custos é usada para desenvolver estratégias superiores e assim obter vantagem competitiva, tema discutido com destaque por Kaplan e Johnson (1987), quando questionavam a relevância da contabilidade gerencial e a maneira como ela poderia contribuir para um diferencial competitivo da organização. O uso da informação de custos na gestão estratégica da empresa deu origem à terminologia gestão estratégica de custos (GEC), com base em estudos sobre o tema (SIMMONDS, 1981; SHANK; GOVINDARAJAN, 1997; McNAIR, 2007; CINQUINI; TENUCCI, 2010) que aprofundaram o entendimento sobre a gestão de custos e sua contribuição por melhores resultados. Nessa busca por melhorias, a GEC auxilia atendendo às demandas mercadológicas e às necessidades de adaptação das organizações, gerando informações para a tomada de decisão e mensuração dos impactos das estratégias nos resultados (SHANK; GOVINDARAJAN, 1997).

A GEC deve ser dinâmica para atender às rápidas mudanças de ambiente e à crescente diversidade de produtos e processos de fabricação. Para atender aos seus propósitos, ela se baseia em três temas-chave: análise do posicionamento estratégico; análise dos direcionadores de custo; e análise da cadeia de valor (SHANK; GOVINDARAJAN, 1997).

Diante de tal contexto, o objetivo do estudo é analisar os processos e práticas da gestão de custos logísticos de uma empresa moveleira. Para atingir o objetivo foram estabelecidos os seguintes objetivos específicos: (a) mapear os processos logísticos da empresa; (b) analisar os principais custos envolvidos nos processos logísticos; (c) relacionar as principais práticas de GEC.

O presente estudo se justifica com base na discussão e identificação dos custos que cada elo gera na gestão logística interna, bem como os processos que estão gerando custos sem agregar valor ao produto/serviço. Dessa forma, o estudo contribui para avanços na mensuração e gestão de custos da logística interna das organizações e das práticas de GEC 
relacionadas. A pesquisa mostra-se relevante à medida que identifica potenciais práticas a serem adotadas com o objetivo de otimizar custos e tempo e incrementar a competitividade das organizações.

O tema objeto deste estudo tem atraído a atenção de vários pesquisadores preocupados com a ocorrência de custos nos processos e nas práticas de logística das empresas. Entre eles pode-se destacar Tondolo e Schneider (2005), Engblom et al. (2012), Souza, Cardoso e Machado (2012).

Este artigo está estruturado em cinco partes. Inicia-se com esta introdução, passa pela revisão da literatura atinente ao tema e pela apresentação dos principais aspectos metodológicos. O estudo contempla ainda a apresentação e análise dos dados e conclusão. Por fim, há a lista das referências utilizadas no desenvolvimento da pesquisa.

\section{Revisão de Literatura}

\subsection{Práticas da Gestão Estratégica de Custos (GEC)}

Segundo Shank e Govindarajan (1997), a relevância e utilidade da GEC estão concentradas no fato de ela possibilitar a realização de análises mais amplas que o tradicional foco contábil a respeito do desempenho das empresas. Assim, ela torna-se um importante instrumento de apoio à tomada de decisões, pois traz informações que irão auxiliar a empresa no alcance de maior competitividade. Na sequência do estudo de Shank e Govindarajan (1997), Cinquini e Tenucci (2010) pesquisaram o uso de várias práticas de GEC, entre elas a gestão dos custos logísticos e outras práticas relacionadas.

Os custos logísticos são compostos por custos de transporte, armazenagem, logística interna, administração, embalagens e custos indiretos, representando uma significativa proporção dos custos da empresa (ENGBLOM et al., 2012). Um método para a gestão dos custos logísticos internos se dá por meio da análise da cadeia de valor interna, apresentado na seção seguinte.

\subsection{Cadeia de Valor}

A cadeia de valor é o conjunto de atividades executadas para projetar, produzir, comercializar, entregar e sustentar um produto. Esse conglomerado de tarefas é dividido em tarefas primárias e de apoio (PORTER, 1989). A cadeia de valor tem início com a origem na matéria-prima e se estende até o descarte do produto pelo último consumidor (BALLOU, 2006).

Conhecer a cadeia de valor permite à empresa identificar onde é criado (ou destruído) valor ao produto (RIEPLE; SINGH, 2010). A análise da cadeia de valor interna inclui analisar os elos que envolvem a compra, produção, venda e distribuição do produto. A análise da cadeia de valor é um método utilizado pelas empresas a fim de compreender melhor o comportamento dos custos e das receitas. Ao gerenciar a cadeia de valor e diagnosticar os determinantes do custo para cada atividade, a empresa consegue obter uma vantagem competitiva em relação às empresas concorrentes (DIACONU, 2009).

Brown, Bessant e Lamming (2000) destacam que apesar de a teoria sugerir simplicidade e clareza na análise da cadeia, apresentando-a de forma linear e sequencial, a 
realidade pode ser muito mais confusa do que essa proposição teórica, tornando mais difícil a tomada de decisões em cadeias de valores complexas, gerando por vezes decisões arbitrárias. Independente da forma que a cadeia de valor é composta, quanto mais empresas presentes na cadeia de valor maior é sua complexidade e mais desafios estarão presentes.

Para gerenciar a cadeia de valor, a empresa pode optar por modelos de baixo custo, que entregue apenas o valor proposto e nada mais, ou o modelo de diferenciação, que realiza apenas as atividades essenciais dentro da empresa e terceiriza as demais atividades (KACHANER; LINDGARDT; MICHAEL, 2011). O estudo de Souza, Cardoso e Machado (2011) dividiu a mensuração e análise dos custos na cadeia de valor em dois aspectos:

a) Mensuração e Análise dos Custos na Cadeia de Valor Interna: essa agregação de valor é medida em função do cumprimento de metas orçamentárias e não da agregação de valor em si. A partir do controle e mensuração dos custos gerados internamente é possível realizar análises em relação aos desvios dos custos nas metas estipuladas.

b) Mensuração e Análise dos custos na Cadeia de Valor Externa: Cada etapa da cadeia de valor externa influencia os processos internos e externos da empresa, afetando as atividades executadas para fazer o produto chegar até o cliente final.

A análise dos custos da cadeia de valor interna, que é o foco desta pesquisa, envolve a análise da movimentação interna e suporte ao processo de produção que também provocam a ocorrência de custos e devem estar contemplados na análise da cadeia (SOUZA; CARDOSO; MACHADO, 2011).

A análise da cadeia de valor é usada como uma ferramenta de gestão estratégica que permite compreender os pontos fortes e as insuficiências das atividades (internas e externas) que compõem a cadeia, além de identificar novas formas de conduzir as atividades a fim de se obterem produtos e serviços com maior agregação de valor (POPESCU; DASCALU, 2011). Dada a sua maior relevância na atual forma de atuação das empresas, a logística tem sido objeto de estudos específicos, inclusive quanto ao seu impacto na cadeia de valor das empresas (PORTER, 1989).

\subsection{Gestão de Custos da Indústria e Varejo}

É tradicional que empresas se organizem em torno da produção e do marketing, pois, a produção é responsável pela fabricação dos produtos e o marketing por viabilizar a sua comercialização (BALLOU, 2006).

Porter (1989) identificou categorias de atividades primárias e secundárias, cuja identificação depende de características específicas da empresa e de sua estratégia. Além (a) das operações, atividades relacionadas à transformação da matéria-prima em produtos; (b) do marketing, responsável pela interface entre a empresa com seus produtos; e os (c) serviços de pré-venda (telemarketing e informações a clientes) e pós-venda (garantia e assistência técnica), Porter (1989) faz referência aos dois âmbitos de atuação da logística, a saber:

a) Logística Interna: composta de atividades como recebimento, armazenagem, distribuição, controle de estoques, manuseio de material e programação de frotas.

b) Logística Externa: atividades relacionadas à coleta, armazenagem e distribuição física do produto para compradores.

31 ISSN 2175-8069, UFSC, Florianópolis, v. 12, n. 25, p. 27-46, jan./abr. 2015 
Uma das formas de avaliação da eficiência logísticas é a mensuração dos seus custos, o que auxilia os gestores na tomada de decisão tanto sobre sistemas internos de operações como na realização de parcerias com fornecedores e distribuidores (FARIAS; COSTA, 2010).

Corroborando esse entendimento, Engblom et al. (2012) enfatizam que os custos logísticos são muito importantes e significativos dentro das empresas, chegando por vezes a mais de $10 \%$ do faturamento. Os autores salientam que esses custos não são muitas vezes possíveis de serem mensurados individualmente por meio de seus componentes, devido às diversas combinações dos eventos geradores. Em estudo com 241 empresas europeias, os autores trazem os componentes de custos e os principais elementos que possuem relação estatística quando trata da geração de custos logísticos (Figura 1).

Observa-se, na Figura 1, aspectos que impactam nos componentes de custos logísticos. Engblom et al. (2012) encontraram quatro componentes que possuem relação positiva com os custos logísticos: (a) tipo de indústria: segmento em que está inserida, exigindo especificidades em alguns dos componentes logísticos; (b) faturamento: volume de produtos transacionados; (3) número de empregados: quantidade de pessoas necessárias para disponibilizar o produto; e (4) nível de internacionalização: quanto maior a internacionalização, mais complexa é sua logística devido ao transporte para o destinatário final no exterior.

Figura 1 - Principais fontes de impacto nos custos logísticos

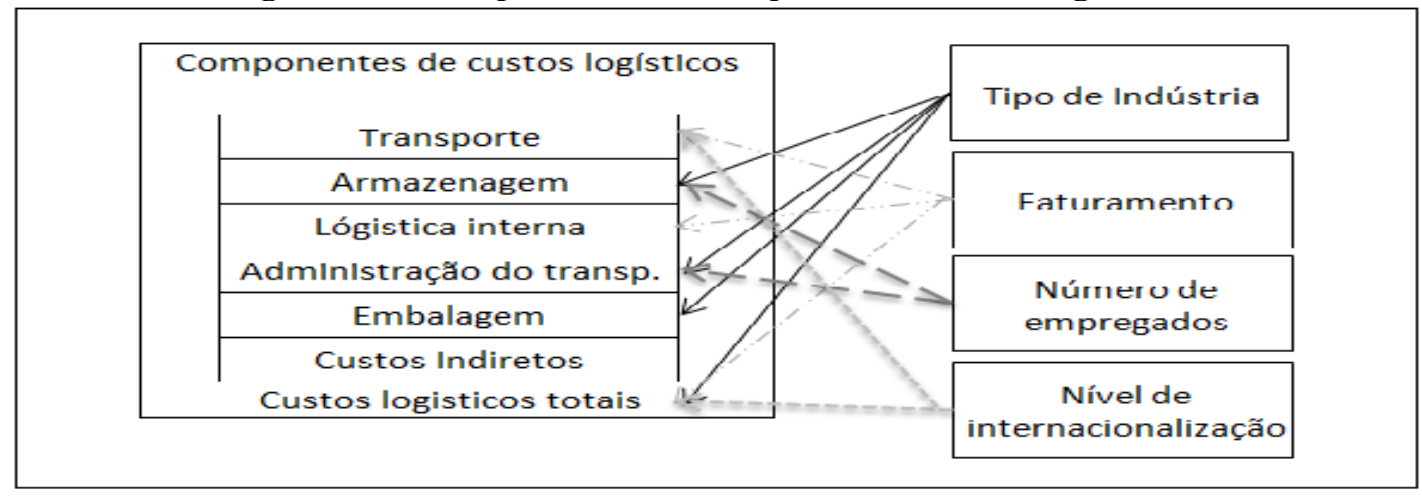

Fonte: Adaptado de Engblom et al. (2012).

Sob o ponto de vista da gestão de custos logísticos internos, encontra-se a importante função de controlar os custos referentes ao processamento de pedidos, transporte, armazenamento e estocagem dos produtos. Na indústria e no varejo, a logística também é responsável por controlar os custos da distribuição das mercadorias aos clientes. A relevância e a expressividade do volume de recursos consumidos nessas atividades têm motivado o desenvolvimento de diversas pesquisas sobre o tema, conforme apresentado na sequência.

\subsection{Estudos Relacionados}

\subsubsection{Estudos Nacionais}

Apresenta-se, no Quadro 1, a estrutura resumida de artigos científicos nacionais recentes que abordam o tema Cadeia de Valor e Logística. 


\begin{tabular}{|c|c|c|}
\hline Autor/Ano & Objetivo & Conclusões \\
\hline $\begin{array}{l}\text { Souza; Cardoso; } \\
\text { Machado, } \\
2012 .\end{array}$ & $\begin{array}{l}\text { Identificar o uso da análise de } \\
\text { custos da cadeia de valor por } \\
\text { empresa multinacional do } \\
\text { segmento petrolífero. }\end{array}$ & $\begin{array}{l}\text { A empresa adota procedimentos de mensuração e } \\
\text { análise dos custos da cadeia de valor, com foco na } \\
\text { redução dos custos e manutenção da qualidade. } \\
\text { Utilizam da GIC, TCO, Custos logísticos e P. Transf. }\end{array}$ \\
\hline $\begin{array}{c}\text { Santos, et al., } \\
2010 .\end{array}$ & $\begin{array}{l}\text { Mostrar como a cadeia de } \\
\text { valor pode contribuir para a } \\
\text { compreensão da formação da } \\
\text { cadeia de suprimentos. }\end{array}$ & $\begin{array}{c}\text { Mostrou a estreita relação entre cadeia de valor e } \\
\text { cadeia de suprimentos, pois foi possível construir a } \\
\text { cadeia de suprimentos da empresa a partir da análise } \\
\text { de sua cadeia de valor. }\end{array}$ \\
\hline $\begin{array}{l}\text { Hofer; Souza; } \\
\text { Robles JR, } \\
2007 .\end{array}$ & $\begin{array}{l}\text { Análise dos métodos de custos } \\
\text { de produção do leite, e analise } \\
\text { da gestão estratégica do setor } \\
\text { integrando os custos da cadeia } \\
\text { de valor. }\end{array}$ & $\begin{array}{c}\text { A cadeia de valor é altamente sensível, tendo em vista } \\
\text { a influência de fatores externos, pois como o Brasil } \\
\text { não é autossuficiente na produção do leite, afeta sua } \\
\text { cadeia e de seus derivados, elevando assim o seu } \\
\text { custo. }\end{array}$ \\
\hline
\end{tabular}

Fonte: Autores citados.

Uma semelhança identificada nos estudos apresentados no Quadro 1 é que a cadeia de valor é significativamente destacada para as empresas realizarem o controle dos custos. Em relação aos custos logísticos presentes na cadeia de valor, os estudos destacaram que permitem compreender a forma e os recursos consumidos pelas empresas se relacionarem com os seus clientes e fornecedores.

\subsubsection{Estudos internacionais}

Apresentam-se, no Quadro 2, os dados gerais de estudos internacionais relacionadas ao tema de pesquisa.

\section{Quadro 2 - Estudos internacionais sobre o tema}

\begin{tabular}{|c|c|c|}
\hline Autor/Ano & Objetivo & Conclusões \\
\hline $\begin{array}{c}\text { Mu; Cui, } \\
2012 .\end{array}$ & $\begin{array}{c}\text { Discutir o mecanismo de } \\
\text { governança para superar } \\
\text { problemas de cooperação, } \\
\text { coordenação e apropriação. }\end{array}$ & $\begin{array}{c}\text { O alto nível de confiança entre as empresas o o incentivo } \\
\text { com base nos interesses comuns da cadeia podem reduzir } \\
\text { problemas de cooperação, coordenação e apropriação. A } \\
\text { governança tem efeitos significativos sobre os custos da CV. }\end{array}$ \\
\hline $\begin{array}{c}\text { Wanstruir um modelo de } \\
2012 .\end{array}$ & $\begin{array}{c}\text { Por DEA, elementos de gestão da cadeia de valor são } \\
\text { cadeia de valor na } \\
\text { construção naval. }\end{array}$ & $\begin{array}{c}\text { distinguidos. O valor das operações internacionais da gestão } \\
\text { da cadeia de valor é apresentado para melhorar o } \\
\text { desempenho na construção naval. }\end{array}$ \\
\hline $\begin{array}{c}\text { Christopher; } \\
\text { Holweg, } \\
2011 .\end{array}$ & $\begin{array}{c}\text { Questionar a abordagem de } \\
\text { que a variabilidade da gestão } \\
\text { da cadeia é prejudicial para } \\
\text { o desempenho da empresa. }\end{array}$ & $\begin{array}{c}\text { Modelos de gestão da cadeia surgem a partir de um período } \\
\text { de relativa estabilidade e que não há evidências de que } \\
\text { haverá turbulência no futuro. }\end{array}$ \\
\hline
\end{tabular}

Fonte: Autores citados.

Grande parte dos estudos que envolvem os temas cadeia de valor e gestão de custos logísticos destaca a relevância do monitoramento principalmente dos custos de transporte. Para tanto, investigam a forma de transporte mais econômica para distribuir os materiais e produtos (de fornecedores a clientes), o que impacta significativamente no custo total da cadeia de valor da empresa. 


\section{Procedimentos Metodológicos}

Dentre as formas de classificar um estudo, e mais especificamente quanto à sua natureza, a pesquisa é classificada como aplicada, visto que o tema é analisado com base em um caso real. Possui características qualitativas quanto à sua forma de análise (GIL, 1999). O estudo também recebe a classificação de pesquisa descritiva, pois, conforme salienta Gil (1999), esse tipo de pesquisa descreve características de determinada população e estabelece relações entre variáveis.

Para a efetivação da pesquisa foi realizado um estudo de caso único, tendo como entidade objeto de estudo uma empresa moveleira de grande porte, com faturamento superior a R\$ 2 bilhões no ano de 2012, situada na região sul do Brasil. Para Yin (2010) o estudo de caso único realiza uma análise contextual aprofundada de uma série de acontecimentos e seus relacionamentos. A realização do estudo de caso único nessa empresa foi instigada devido ao destaque que seus produtos possuem no mercado nacional, além das exportações para países da América do Sul e também no âmbito nacional, mesmo atuando em dois segmentos de grande concorrência.

Para organização geral e melhor direcionamento dos trabalhos foi desenvolvido um protocolo de estudo, contemplando a amplitude conceitual, definição do perfil dos entrevistados, data das visitas à empresa e roteiro semiestruturado de entrevista. As entrevistas foram realizadas com diversos gerentes (comercial, logística, controladoria, industrial). Além deles, foram também entrevistados a analista de recebimento fiscal e o encarregado do departamento financeiro. A estrutura das questões usadas nas entrevistas foi elaborada com base no estudo de Souza, Cardoso e Machado (2011), Cinquini e Tenucci (2010) e Engblom et al. (2012).

As entrevistas foram gravadas e posteriormente transcritas para incorporação em uma ferramenta computacional de análise de conteúdo (software sphinx), que auxiliou na análise mais apurada e com menor grau de subjetividade em relação às respostas dos entrevistados.

Para a análise de conteúdo e depois importação das entrevistas no software, realizouse a tarefa de categorização dos conteúdos. Foram criadas 11 categorias baseadas na literatura de custos logísticos na cadeia de valor, ligadas às práticas de gestão estratégica de custos, elos e fatores geradores de custos. A segunda tarefa trata da análise léxica, que exigiu 'limpeza' das palavras que não apresentavam riqueza semântica, como conectores e palavras instrumentais. Depois de realizado o tratamento dos léxicos das entrevistas, os dados foram cruzados com as categorias gerando um mapa fatorial dos principais pontos das entrevistas e suas relações (FREITAS et al., 2009).

A análise documental foi realizada nos fluxos de processos, fluxo de caixa anual e no orçamento mensal da empresa. Esse procedimento teve como objetivo identificar os custos mais significativos relativos às matérias-primas da indústria, custos logísticos de transporte, custos de montagem e dos demais processos. As observações foram realizadas no centro de distribuição e nos setores de marcenaria, costura e química, a fim de identificar os processos que compõem a cadeia interna de valor da empresa e ratificar dados obtidos nas entrevistas e análise documental. 


\section{Análise dos Dados}

\subsection{Caracterização da Entidade Objeto do Estudo}

A empresa objeto da pesquisa foi fundada em 1959, fabricando esquadrias em um pequeno depósito de madeiras. Com a expansão da empresa, ela passou a incorporar vendas de material de construção, ferragens, móveis e eletrodomésticos. Nos anos seguintes, a empresa passou a fabricar móveis estofados e iniciou a fabricação de espumas de poliuretano para seu próprio uso. Em seguida, passou a fabricar colchões e, em 1982, foi aberta a primeira loja de varejo.

A empresa possui destaque no varejo devido às 80 lojas próprias distribuídas nos estados da região Sul do Brasil, e na indústria pela fabricação de móveis de madeira e estofados, colchões, espumas, solados e laminados de látex. Sua indústria e centro de distribuição estão situados em uma cidade da região metropolitana de Porto Alegre.

Recentemente a empresa expandiu seus negócios e tornou-se um grupo com diversas unidades. Além das unidades de destaque, que são indústria moveleira e varejo, ela também possui unidades no segmento de transportadora, importadora, seguradora, financeira, construtora, atacado de pneus, máquinas e ferramentas, móveis planejados, consórcio e representante de produtos tecnológicos portáteis. O faturamento de todas as unidades do grupo superou o valor de $\mathrm{R} \$ 2$ bilhões no ano de 2012, o que, de acordo com a classificação do BNDES (2011), a enquadra como empresa de grande porte.

\subsection{Observações nos Processos da Indústria e Varejo}

As observações e entrevistas foram previamente agendadas por meio de contatos telefônicos. Os entrevistados se mostraram receptivos aos questionamentos trazidos pelos pesquisadores. Posteriormente às entrevistas, manteve-se contato por meio de correio eletrônico para coletar informações informacionais, necessárias para análise comparativa com a literatura.

Segundo o auxiliar financeiro, o centro administrativo da empresa é responsável pela mensuração, análise e controle dos custos de todos os setores e unidades da empresa. Cada setor possui um orçamento que define quanto poderá ser gasto mensalmente, segundo o plano estratégico elaborado e aprovado no início de cada ano. Dessa forma, a controladoria consegue monitorar os custos da empresa. Ocorrendo a necessidade de um gasto que exceda o orçamento mensal, ele deve antes ser aprovado pela controladoria e direção geral da empresa.

A empresa possui o mapeamento da cadeia de valor, tanto do comércio quanto da indústria. As seções que seguem trazem os detalhamentos das cadeias de valor e da gestão dos custos logísticos nesses dois segmentos.

\subsubsection{Segmento Indústria}

A divisão da produção da empresa se dá por meio de linhas que atendem a determinados segmentos, atuando em nichos de mercado diferentes e com estratégias bem definidas para não comprometer o preço e a imagem dos seus produtos diante dos clientes. Para buscar a diferenciação por preço a empresa conta com o recurso de produzir as diferentes 
linhas de produtos no mesmo parque fabril, o que diminui o custo de produção e possibilita a prática de menores preços.

A cadeia de valor da indústria começa na matéria-prima que vem para a produção, com a chegada de vários itens e de diversos fornecedores e, por meio deles, a empresa realiza o processo produtivo para a fabricação de um bem. Este bem só é produzido quando há pedidos, significando que não há produção para estocagem, pois a empresa não possui espaço físico suficiente para isso. Em alguns casos, a matéria-prima (espumas) é produzida pela própria empresa, dado que em uma das unidades elas são utilizadas na produção de colchões, estofados e cadeiras. Para a fabricação dos móveis a empresa compra a madeira bruta e realiza todo o processo de secagem. Com essa matéria-prima, fabricam-se móveis que depois de prontos seguem para o setor de embalagem e são armazenados em pequeno estoque até que todos os produtos do pedido estejam prontos para serem carregados e entregues ao cliente.

Todos os produtos fabricados pela empresa acompanham um rigoroso controle de qualidade visto que eles devem proporcionar durabilidade. Isso é particularmente importante dado que a empresa oferece cinco anos de garantia e assistência na maioria de seus produtos. A Figura 2 apresenta o mapeamento dessa cadeia de valor.

\section{Figura 2 - Cadeia de valor da indústria}

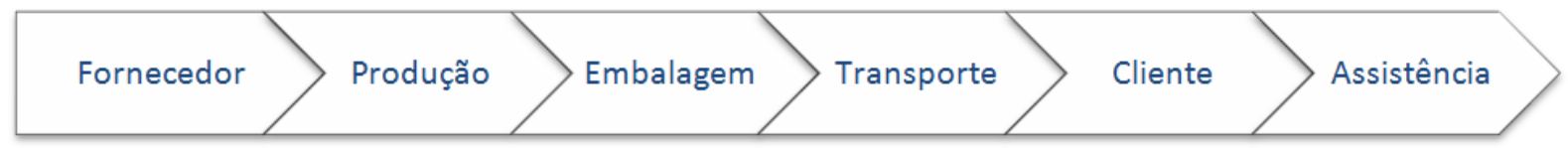

Fonte: Dados da pesquisa.

Um dos produtos fabricados pela empresa é o estofado. Sua cadeia de valor inicia na compra da matéria-prima, neste caso a madeira passa pelo setor da marcenaria onde a madeira é tratada e são formadas as peças que compõem o esqueleto do estofado. Em seguida, esse esqueleto vai para o setor da metalúrgica onde são instalados os braços de ferro que proporcionam suporte ao esqueleto, pois a madeira não consegue sustentar todo o peso do estofado. Posteriormente, o estofado segue para o setor de costura, onde são agregados todos os componentes de espuma e, por final, vem a montagem. A Figura 3 ilustra a cadeia de valor da fabricação dos estofados.

Figura 3 - Cadeia de valor da fabricação de estofados

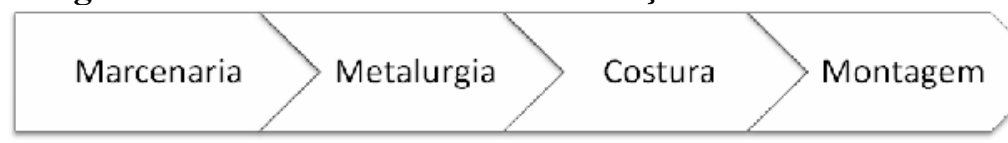

Fonte: Dados da pesquisa.

A indústria terceiriza a costura de capas de estofados e outros produtos desse setor quando há um pedido muito grande e o setor não consegue atender à demanda. Pela agilidade na produção, em alguns casos os pedidos são realizados pela manhã e entregues à tarde. Os processos da gestão dos custos logísticos da indústria englobam os elos ilustrados na Figura 4. 
Práticas de gestão de custos logísticos internos: estudo de caso em empresa moveleira do sul do Brasil...

Figura 4 - Processos da gestão dos custos logísticos da indústria

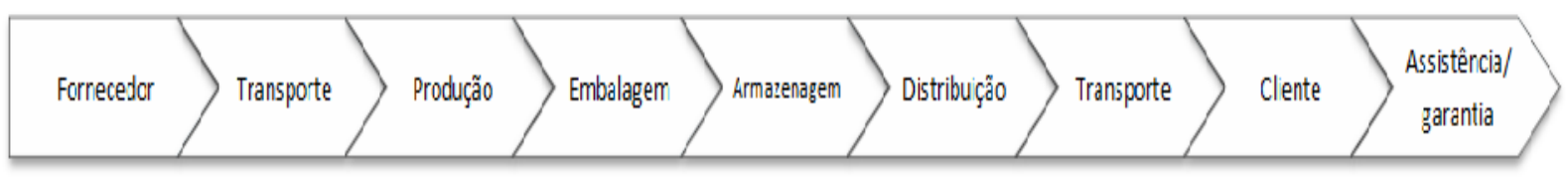

Fonte: Dados da pesquisa.

No que se refere a fornecedores, 35\% deles são do Rio Grande do Sul, e 47\%, de São Paulo. A matéria-prima proveniente de São Paulo é transportada por caminhões próprios em seus retornos de viagens, o que minimiza os custos com fretes.

\subsubsection{Segmento Varejo}

Os processos da gestão de custos logísticos do varejo têm início no transporte de produtos até o centro de distribuições da empresa, registrados e controlados com o auxílio de um leitor de código de barras. Posteriormente são alocados em paletes e, em seguida, transportados por transpaleteiras até seus endereços específicos onde são elevados com empilhadeiras. Quando há um pedido de compra de um cliente, o produto sai de seu endereço por meio de uma empilhadeira, transportado até o caminhão por meio da transpaleteira, conferido pelo conferente e então carregado no caminhão, que realiza a entrega direta, ou seja, transporta o produto até a residência do cliente.

Segundo o gerente de logística, o varejo da empresa possui uma frota de 50 caminhões próprios e utiliza outros 50 caminhões terceirizados, pois há necessidade de muitos caminhões para a realização das entregas diretas e também das entregas de ressuprimento que são os fretes de mercadorias do centro de distribuição até a loja.

Com base nas observações, foi possível mapear os processos da gestão dos custos logísticos do varejo como segue na Figura 5:

Figura 5 - Processos da gestão dos custos logísticos do varejo

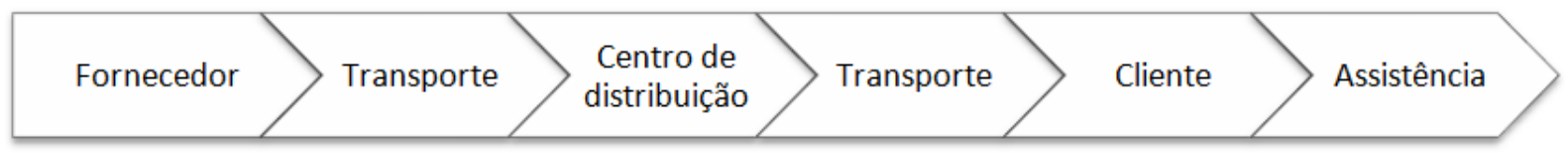

Fonte: Dados da pesquisa.

Os pedidos são gerados pelas lojas que, em alguns casos, possuem o produto estocado dentro da loja. Outra alternativa ocorre quando os pedidos são encaminhados ao centro de distribuição, que, na sequência, realiza a entrega da mercadoria diretamente ao cliente. Essa alternativa tem como objetivo principal reduzir os custos, agilizar o processo logístico e bem atender o cliente. Esse procedimento converge com o entendimento de Porter (1989), para o qual a cadeia de valor da empresa busca o menor custo possível sem perda de qualidade.

\subsection{Análise Documental dos Custos}

Foram analisados o fluxo de caixa anual, o orçamento anual dividido em períodos mensais e os mapas de fluxos dos processos. No segmento indústria moveleira, a análise do fluxo de caixa apresentava os valores referentes a cada produto comprado. Como não foi autorizada a publicação dos valores, estes foram transformados para o formato de porcentagem. Esses dados evidenciaram que os custos de aquisição de mercadorias na linha 
de colchões representam aproximadamente $10 \%$ das compras, enquanto que a linha de madeira representa algo próximo a $35 \%$. Os $55 \%$ restantes ficam a cargo das compras relacionadas a linha de estofados.

O custo do transporte dos produtos fabricados dentro da empresa até suas lojas é de responsabilidade da indústria, enquanto a entrega e a montagem das mercadorias vendidas na loja até os respectivos clientes são realizadas por empresas terceirizadas. Esse serviço gera um custo de aproximadamente $4 \%$ sobre o valor da mercadoria.

No segmento varejo, em relação aos gastos fixos, o aluguel representa o maior dos custos quando comparado aos custos referentes à energia elétrica, água, telefone, segurança patrimonial, combustível, material de expediente e serviços de terceiros.

O custo líquido de aquisição de mercadorias representa $39,5 \%$ da receita bruta; o frete sobre vendas representa $4 \%$; a propaganda, $3 \%$; a comissão de vendedores, $1,8 \%$; encargos sem comissão, 1,4\%; comissão do gerente, $0,5 \%$; e função gratificada do gerente, $0,2 \%$. Esses dados já estavam disponibilizados no formato de porcentagem.

Segundo a analista do recebimento fiscal, para atingir a diferenciação por imagem o varejo investe muito em marketing, sendo que recebem verba de propaganda conforme o volume de faturamento e margem. A verba de propaganda também é cobrada dos fornecedores, pois o fornecedor que não destina 3\% do valor de seu produto para a empresa não tem seu produto divulgado nas propagandas.

\subsection{Análise das Entrevistas}

Como técnica de análise de dados, foi realizada a análise de conteúdo das entrevistas com auxílio da ferramenta computacional Software Sphinx. O objetivo é maximizar as análises das entrevistas, cruzando as informações com a teoria abordada. Apresenta-se, no Quadro 3, o perfil dos entrevistados.

Quadro 3 - Perfil dos entrevistados

\begin{tabular}{|c|c|c|}
\hline Cargo & Formação & Tempo de Serviço \\
\hline Gerente do Comércio & Pós-graduação em Controladoria & 15 anos \\
\hline Gerente de Logística & Graduação em Administração & 7 anos \\
\hline Gerente de Controladoria & Pós-graduação em Controladoria & 4 anos \\
\hline Auxiliar Financeiro & Graduação em Administração incompleta & 13 anos \\
\hline Analista de Recebimento Fiscal & Técnico em Administração & 2 anos \\
\hline
\end{tabular}

Fonte: Dados da pesquisa.

De acordo com o gerente de controladoria, para buscar competitividade em relação à concorrência, a indústria moveleira adota estratégias de diferenciação e enfoque, dependendo do produto. Em relação à estratégia de enfoque, a empresa concentra esforços em determinado mercado onde desenvolve produtos personalizados para cada cliente. Para alguns clientes a empresa necessita formar o preço baseado na demanda, ou seja, cabe à indústria identificar a rentabilidade obtida com os preços de vendas propostos aos clientes, restando apenas a decisão de aceitar ou não os pedidos.

Apresentam-se, na Figura 6, o mapa fatorial das entrevistas realizadas, os principais temas abordados e suas relações com as categorias estudadas. As marcações escuras se referem a 11 categorias elaboradas com base na teoria estudada e as marcações claras são os 
léxicos que apresentam os conteúdos abordados nas entrevistas. A proximidade ou distância, entre os elementos, bem como sua disposição no mapa, indica a relação entre os conteúdos.

Pode se observar que o controle está presente no centro temático das abordagens dos entrevistados. A empresa, segundo os entrevistados, cresceu muito rapidamente e necessita ter mais controle sobre seus processos para manter a qualidade e rentabilidade determinada no seu planejamento estratégico. Isso atende ao objetivo de continuar a expansão, representada pela abertura de dez novas filiais a cada ano.

Para redução de custos e controle da qualidade, a empresa apresenta alto grau de verticalização em suas atividades. As relacionadas à cadeia de valor externa da empresa têm foco no monitoramento do mercado/concorrência, na satisfação dos clientes e na compra de produtos para comercialização em suas lojas, enquanto o foco da cadeia de valor interna é a gestão dos custos logísticos, principalmente o de transporte e os fatores determinantes de custos, uma vez que, havendo o enfoque da diferenciação na indústria, ocorre maior custo na matéria-prima e nos processos utilizados na produção. Isso se confirma no distanciamento entre os elementos de cadeia de valor na Figura 6.

No item que se refere à qualidade/eficiência, os entrevistados apresentaram um discurso ligando este tópico com a estratégia da empresa e que a matéria-prima é um dos principais componentes relacionados a esta. Ainda, o léxico relativo à diferenciação se encontra em uma distância equivalente entre a qualidade/eficiência e o mercado/concorrência, dada a importância para os dois tópicos.

O tamanho dos círculos representa a frequência dos léxicos nas respostas. De maneira geral, não houve predominância de um tema sobre o outro, observando-se que os tamanhos dos léxicos são semelhantes. O único item que é apresentado de maneira mais significativa é o círculo claro, que se encontra no centro do mapa. Não se trata de um léxico específico, mas é o acumulado dos léxicos de menor expressão que não obtiveram uma frequência mínima de quatro citações. A presente análise focou nos léxicos com maior representatividade nas respostas dos entrevistados.

Percebe-se, pela análise da Figura 6, três agrupamentos nas temáticas tratadas. O primeiro se refere aos temas ligados à cadeia de valor interna, o segundo é referente à cadeia de valor externa e por fim os ligados ao controle, dos quais os dois primeiros são tratados mais substancialmente. Cada um dos agrupamentos apresenta as principais informações ligadas a ele. $\mathrm{Na}$ cadeia de valor interna que os respondentes vinculam a uma preocupação com os custos logísticos e seus processos, principalmente o de transporte, também perpassa o agrupamento de controle em menor intensidade, porém mais ligado a itens de mensuração.

As práticas de GEC estão próximas da categoria controle, no entanto não é encontrado nenhum léxico próximo que evidencie tais práticas. Embora algumas práticas de GEC sejam realizadas pela empresa, e alguns dos entrevistados (gerente do comércio e gerente de controladoria) tenham presentes os nomes técnicos destas, de maneira geral não são identificados claramente, exemplificados no preço interno de transferência que é realizado entre os departamentos e unidades da empresa, sem, no entanto, estar assim definido.

As análises realizadas no estudo foram potencializadas com o uso e a análise do mapa fatorial. De fato, as relações encontradas permitiram uma abordagem mais aprofundada sobre as respostas de cada entrevistado e relações não tão evidentes, apresentadas ao longo da análise. 


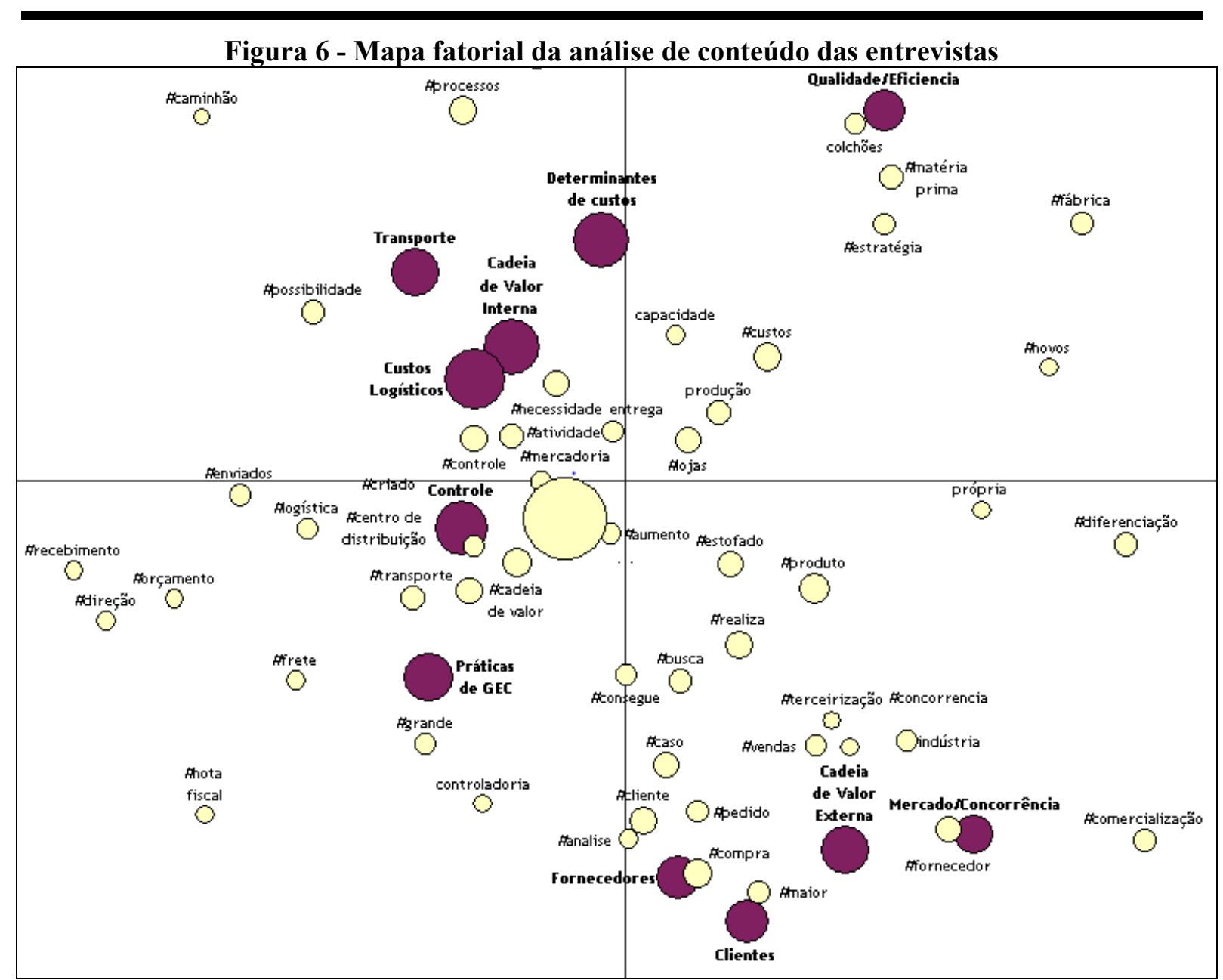

Fonte: Dados da pesquisa.

Elaborado a partir das entrevistas, o Quadro 4 apresenta as principais práticas de GEC e as atividades realizadas pela empresa.

\section{Quadro 4 - Práticas de GEC na cadeia de valor da empresa}

\begin{tabular}{|c|l|}
\hline Práticas de GEC & \multicolumn{1}{|c|}{ Atividades realizadas pela empresa na cadeia de valor } \\
\hline $\begin{array}{c}\text { Determinantes de } \\
\text { custos }\end{array}$ & $\begin{array}{l}\text { A empresa realiza controle sobre os principais componentes que geram custos. Para } \\
\text { redução dos custos e controle da qualidade investe em tecnologia e na verticalização das } \\
\text { atividades. }\end{array}$ \\
\hline $\begin{array}{c}\text { Preço de } \\
\text { transferência } \\
\text { interno }\end{array}$ & $\begin{array}{l}\text { Praticado entre as unidades do grupo, inclusive com a ocorrência de empréstimos } \\
\text { financeiros entre elas. Se uma das unidades extrapolar o orçamento ocorre um } \\
\text { empréstimo, posteriormente devolvido para a unidade que o concedeu. }\end{array}$ \\
\hline $\begin{array}{c}\text { Custos logísticos } \\
\text { valores investidos em marketing. Trabalha com estoques mínimos e entrega o produto ao } \\
\text { cliente o mais rápido possível para diminuir o tempo de estocagem. Possui cerca de 50\% } \\
\text { de frota própria e 50\% de terceirização de outros veículos, que pode ser aumentada com a } \\
\text { demanda sem a criação de custos fixos. }\end{array}$ \\
$\begin{array}{c}\text { Custo total de uso } \\
\text { e propriedade } \\
\text { (TCO) }\end{array}$ & $\begin{array}{l}\text { A compra de máquinas, equipamentos e veículos são gerenciados pelo departamento de } \\
\text { compras e autorizados pela controladoria. Pelo enfoque dado à qualidade, a empresa } \\
\text { investe em tecnologia e, como isso envolve valores significativos, a empresa analisa } \\
\text { todos os custos envolvidos, inclusive os tradicionalmente ocultos. }\end{array}$ \\
\hline
\end{tabular}


Práticas de gestão de custos logísticos internos: estudo de caso em empresa moveleira do sul do Brasil...

\begin{tabular}{|c|l|}
\hline $\begin{array}{c}\text { Gestão } \\
\text { interorganizacional } \\
\text { de custos (GIC) }\end{array}$ & $\begin{array}{l}\text { A empresa é essencialmente verticalizada, mas realiza a GIC com fornecedores de } \\
\text { tecidos, especialmente para colchões hospitalares e clínicas que exigem certificação da } \\
\text { ANVISA. A gestão em conjunto com o parceiro visa redução de custos, desenvolvimento } \\
\text { de novas linhas de produtos e manutenção da qualidade estabelecida pela empresa. }\end{array}$ \\
\hline $\begin{array}{c}\text { Custeio baseado } \\
\text { em atividades }\end{array}$ & $\begin{array}{l}\text { Não realiza o custeio baseado em atividades. Utiliza o tradicional método de custeio por } \\
\text { absorção. }\end{array}$ \\
\hline $\begin{array}{c}\text { Análise de } \\
\text { concorrentes }\end{array}$ & $\begin{array}{l}\text { A empresa monitora os principais concorrentes, verificando mix de produtos e tecnologia } \\
\text { usada. Participa de feiras internacionais. A empresa também determina que cada } \\
\text { responsável por compras monitore o mercado de um tipo de produto e passe informações } \\
\text { para controladoria. }\end{array}$ \\
\hline
\end{tabular}

Fonte: Dados da pesquisa.

Conforme apresentado no Quadro 4, a empresa não realiza todas as práticas de gestão estratégica de custos na cadeia de valor elencadas por Cinquini e Tenucci (2010), no entanto realiza um controle bastante aprimorado daqueles custos que mais impactam sobre seus resultados. Ao mesmo tempo, investe também em novas tecnologias para redução de custos e no aumento de capacidade com o espaço e mão de obra disponível, mediante implantação de novo ERP e na robotização de parte da produção. Essas ocorrências são confirmadas pelo controller da empresa ao afirmar que ela cresceu muito rapidamente e que agora está focada na melhoria dos processos a fim de reduzir custos.

Identificou-se por meio das entrevistas com o gerente de comércio e com o gerente de controladoria a importância do direcionamento da empresa para o controle e mensuração dos processos e custos, no entanto não fica claro uma preocupação quanto ao método de custeio. A empresa utiliza o método tradicional por absorção, contrariando o que preceituam Souza, Cardoso e Machado (2011) ao afirmarem que o ABC seria o mais indicado devido a melhor identificação dos fatores geradores de custos e redução das arbitrárias alocações de custos por meio de rateios.

Em relação aos determinantes de custos, os gerentes de logística, do comércio, de controladoria e o auxiliar financeiro não elencaram grau de importância entre eles, porém o determinante (a) qualidade está presente nas respostas de todos os entrevistados, ligada principalmente à estratégia da indústria. Outros determinantes trazidos foram: (b) tecnologia, devido a empresa buscar aumento de capacidade, sem poder aumentar os turnos, o que também está ligado ao ganho de escala e aproveitamento da capacidade; (c) localização pela proximidade do centro de distribuição da maioria das lojas, o que gera menor custo de transporte; (d) experiência, que por sua estrutura verticalizada necessita de know-how sobre diversos processos; (e) armazenagem, na qual o produto que primeiro entrar será o primeiro a sair, bem como o controle sobre o tempo de armazenamento e alerta caso esteja com tempo demasiadamente longo; (f) matéria-prima, principalmente no que se refere à qualidade; e (g) legislação, citada principalmente pela recente lei dos turnos de motorista, que pode provocar gargalos no transporte, havendo destinos que necessitam de motorista adicional para revezamento.

Segundo informações obtidas na entrevista com a responsável pela controladoria, a empresa alcançou a diferenciação no design devido a uma equipe de técnicos que desenvolvem produtos baseados nos 'desejos e necessidades' dos principais clientes. Acrescentou que para alcançar um design diferenciado a empresa tem o auxílio de cinco máquinas bordadeiras de última geração, importadas da China, da Itália e da Alemanha.

Relacionando os achados da pesquisa com as cinco categorias de atividades primárias apresentadas por Porter (1989), evidencia-se que: 
a) Logística Interna: em relação ao segmento indústria, identificam-se as atividades relacionadas ao recebimento, armazenamento e distribuição dos insumos dentro do parque fabril. Já na área do varejo, as atividades são de recebimento, armazenamento e expedição das mercadorias para as 80 lojas. A empresa conta com o auxílio da tecnologia para organizar as mercadorias no estoque, indicar quando há a necessidade de compra de alguma mercadoria ou matéria-prima que está com estoque baixo; a tecnologia também ajuda a localizar produtos nos respectivos endereços do centro de distribuição.

b) Operações: são as atividades relacionadas à transformação da matéria-prima no produto final. $\mathrm{Na}$ indústria, alguns componentes são produzidos pela própria empresa, tais como: molas, espumas, bordados, pés e estruturas de madeira, o que resulta em maior qualidade dos materiais utilizados, além de ser um diferencial competitivo em nível de preço. Para isso, são utilizadas máquinas e equipamentos de alta tecnologia, minimizando o custo desses insumos. Outro fator relevante é a constante pesquisa por materiais alternativos e que proporcionem a mesma qualidade ao produto com menor custo.

c) Logística Externa: é a atividade relacionada à coleta, armazenamento e distribuição física do produto para os clientes, além da terceirização de metade da frota de veículos para garantir a agilidade na entrega dos produtos aos clientes.

d) Marketing e Vendas: a empresa possui um departamento específico para o marketing e a divulgação dos produtos fabricados. Essa divulgação também ocorre com outros produtos disponíveis nas lojas, desde que o fornecedor da marca pague à empresa 3\% do valor do produto como verba de propaganda.

Pelo fato de a empresa estudada ser de grande porte, ficou evidente a preocupação atribuída à tecnologia em meio à cadeia de valor interna. De fato, pela observação notou-se o emprego de tecnologia de ponta na produção e nos sistemas de informações, possibilitando agilizar os processos da cadeia e auxiliando na organização dos produtos no estoque. Essas constatações in loco ratificam informações prestadas pelo gerente de controladoria. Essa verificação também ocorre na agilidade de movimentação dos estoques, garantida por meio da utilização de transpaleteiras e empilhadeiras elétricas, que são responsáveis em conduzir os produtos até seus respectivos endereços dentro do centro de distribuição.

A empresa detém um grande diferencial por possuir, em meio ao seu parque fabril, setores que produzem matérias-primas para a fabricação dos móveis. Esse diferencial da verticalização, além de garantir mais qualidade nos produtos e menos custos com insumos, contribui para a redução dos custos da logística interna, pois evita custos de transporte de fornecedores caso utilizasse abastecimento externo.

\section{Conclusão}

Constatou-se ao analisar as práticas e processos da gestão de custos logísticos internos que, quanto mais pessoas e áreas participam dos processos, maiores são as probabilidades de gerar custos sem agregar valor nenhum ao produto.

A empresa usa a análise da cadeia de valor como instrumento estratégico para manterse competitivamente no mercado. Além de gerenciar sua cadeia de valor, também observa a 
cadeia dos seus concorrentes e, a partir dessas informações, administra cuidadosamente os fatores determinantes de custos para conseguir vantagem competitiva na qualidade e no custo dos produtos. Nesse sentido, com base nas informações coletadas e na análise da cadeia logística de valor interna, é possível verificar que a empresa utiliza parcialmente instrumentos e práticas de gestão recomendados pela literatura.

O processo da gestão de custos logísticos que mais gera custos é o transporte, devido à grande demanda de entregas em locais distantes e pela nova legislação que regula a atuação dos condutores em viagens mais longas. $O$ uso de centro de distribuição e do autoabastecimento de parte da matéria-prima ajuda na redução dos custos de transportes.

Outros achados da pesquisa possibilitaram constatar que a empresa adota parte das orientações dadas por Porter (1989) quanto ao processamento das atividades logísticas bem como a análise da cadeia de valor apresentada por Shank e Govindarajan (1987) no âmbito da gestão estratégica de custos.

Como sugestão para futuros estudos, indica-se o desenvolvimento de pesquisa mais ampla das práticas de gestão estratégica de custos relativos à gestão de custos logísticos em empresas da região. $\mathrm{O}$ uso de amostra de maior quantidade de empresas e de diferentes segmentos de negócios pode possibilitar o alcance de maiores inferências sobre a gestão de custos logísticos das organizações.

\section{Referências}

BALLOU, R. H. Gerenciamento da cadeia de suprimentos: logística empresarial. 5. ed. Porto Alegre: Bookmann, 2006.

BANCO NACIONAL DE DESENVOLVIMENTO ECONÔMICO E SOCIAL - BNDES. Carta Circular n 34/2011 - Normas Reguladoras do Produto BNDES Automático. Setembro, 2011.

BROWN. S; BESSANT, J.; LAMMING, R. Strategic operations management. Oxford: Butterworth Heinemann, 2000.

CHRISTOPHER, M.; HOLWEG, M. "Supply chain 2.0": managing supply chains in the era of turbulence. International Journal of Physical Distribution \& Logistics Management, v. 41, n. 1, p. 63-82, 2011.

CINQUINI, L.; TENUCCI, A. Strategic management accounting and business strategy: a loose coupling? Journal of Accounting \& Organizational Change, v. 6, n. 2 p. 228-259, 2010 .

DIACONU, L. Strategic options of the low-cost companies. The annals of the "Ştefan cel Mare" University Suceava. Fascicle of the Faculty of Economics and Public

Administration, v. 9, n. 1, p. 81-87, 2009.

ENGBLOM, J.; SOLAKIVI, T.; T'OYLI, J.; OJALA, L. Multiple-method analysis of logistics costs. International Journal Production Economics, v. 137, p. 29-35, mai. 2012. 
FARIAS, A. C.; COSTA, M.F.G. Gestão de custos logísticos. 1. ed. São Paulo: Atlas, 2010.

FREITAS, H.; JANISSEK-MUNIZ, R.; COSTA, R. S.; ANDRIOTTI, F. K.; FREITAS, P. H. N. R. Saiba tudo sobre instalação, produtos e estágios de uso associados às diferentes etapas de uma pesquisa. Coleta de dados, detalhes de amostragem e digitação, diversos elementos de tratamentos e análise de resultados. Porto Alegre/RS: Sphinx 2009.

GIL, A. C. Métodos e técnicas de pesquisa social. 5. ed. São Paulo: Atlas, 1999.

HOFER, E.; SOUZA, J. A.; ROBLES JR, A. Gestão estratégica de custos na cadeia de valor do leite e derivados. Custos@Agronegócio, v. 3, Ed. Especial, p. 02-17, maio/2007.

KACHANER, N.; LINDGARDT, Z.; MICHAEL, D. Innovating low-cost business models. Emerald Group Publishing Limited, v. 39, n. 2, p. 43-48, 2011.

KAPLAN, R. S.; JOHNSON, H. T. Relevance lost: the rise and fall of management accounting. Boston: Harvard Business School Press, 1987.

McNAIR, C. J. Beyond the boundaries: future trends in cost management. Cost Management, v. 21, n. 1, p. 10-21, Jan/Feb 2007.

MU, L.; CUI, X. An experimental research on governance mechanisms for cost of value chain. Nankai Business Review International, v. 3, n. 2, p. 199-218, 2012.

POPESCU, M.; DASCALU, A. Value chain analysis in quality management context. Bulletin of the Transilvania University of Braşov. Economic Sciences, v. 4, n. 2, p.121-128, 2011.

PORTER, M. Vantagem competitiva. 24. ed. Rio de Janeiro: Campus, 1989.

RIEPLE, A.; SINGH, R. A value chain analysis of the organic cotton industry: the case of UK retailers and Indian suppliers. Ecological Economics, v. 69, n. 11, p. 2292-2303, jul. 2010.

ROCHA, W; BORINELLI, M. L. Análise estratégica de cadeia de valor: um estudo exploratório do segmento indústria - varejo. Revista Contemporânea de Contabilidade, v. 1, n. 7, p. 145-165, jan./jun. 2007.

SANTOS, C. M. S.; LEITE, M. S. A.; LUCENA, A. D.; GRILO JÚNIOR, T. F. Evoluindo da cadeia de valor para cadeia de suprimentos. Revista Produção Online, v. 10, n. 4, p. 753 778, dez. 2010.

SHANK, J. K.; GOVINDARAJAN, V. A revolução dos custos. 6. ed. Rio de Janeiro: Campus, 1997.

SIMMONDS, K. Strategic management accounting. Management Accounting, v. 59, p. 2629, 1981. 
SOUZA, M. A.; CARDOSO, M. F.; MACHADO, R. Análise de custos na cadeia de valor: estudo de caso em uma empresa multinacional do setor petrolífero. Revista de Informação Contábil, v. 5, n. 4, p. 01-25, out./dez. 2011.

TONDOLO, V. A. G.; SCHNEIDER, L. C. Vantagens logísticas e cadeia de valor na rede de empresas: o caso de uma rede gaúcha de pequenas farmácias. Alcance, v. 12, n.2, p. 143-160, mai./ago. 2005.

WANG, Y. Evaluating value chain management simulation based on GEM\&DEA.

International Review on Computers and Software, v. 7, n. 2, p. 879-884, mar. 2012.

YIN, R. K. Estudo de caso: planejamento e métodos. 2. ed. Porto Alegre: Bookman, 2010. 
